\title{
¿ES ALGO LA NOVELA? PASOS PRELIMINARES HACIA UNA NUEVA DEFINICIÓN
}

\author{
IS THE NOVEL SUCH A THING AS A THING? PRELIMINARY \\ STEPS TOWARDS A NEW DEFINITION
}

Miguel ALONSO LAVANDERO

Universidad de Oviedo uo236950@uniovi.es

Resumen: En la primera sección de este artículo se defienden dos nociones básicas: (1) que es inútil buscar una definición general que pueda aplicarse a todos los textos que denominamos con la palabra novela, pues el término no designa un único género de cosas, y (2) que sí tiene sentido, sin embargo, formular definiciones de menor alcance que sirvan para distinguir diferentes clases de novelas, pero que trasciendan las categorías convencionales, formales y temáticas que constituyen la base de las clasificaciones al uso. Después, en la segunda sección, se proponen algunos puntos de referencia para elaborar una definición de este segundo tipo siguiendo un enfoque experiencialista.

Palabras clave: Teoría de la novela, teoría de los géneros, narratología.

Abstract: In the first section of this paper I argue two basic notions: (1) that there is no point in searching for a general definition that can be applied to every text designated by the word "novel", since the term does not label a single kind of things, and (2) that it does make sense, however, elaborating definitions of lesser scope that distinguish different kinds of novels while transcending the conventional, formal, and thematic categories that are usually considered when formulating a definition of the genre. Then, in the second section, I posit some points of reference that can be used to elaborate a definition of this second sort from an experientialist approach.

Keywords: Theory of the novel, genre theory, narratology. 


\section{1 ¿Hay una novela o hay muchas novelas?}

Suele decirse que lo que caracteriza a la novela en cuanto género literario es, precisamente, su falta de características peculiares. Cela, por ejemplo, consideraba que una novela es «todo aquello que, editado en forma de libro, admite debajo del título, y entre paréntesis, la palabra novela» (Cela, 1953: 9). Javier Cercas ha ido todavía más lejos y ha llegado a decir que una novela es «todo aquello que se lee como tal», de modo que «si algún lector fuese capaz de leer la guía de teléfonos de Madrid como una novela, la guía de teléfonos de Madrid sería una novela» (Cercas, 2011).

Tanto Cela como Cercas proponen una noción rigurosamente pragmática del género. Ambos dan por hecho que todos los libros que denominamos novelas se distinguen de otras clases de textos porque ofrecen un tipo particular de experiencia de lectura. El problema es que no especifican en qué consiste esa experiencia, de manera que, en último término, sus definiciones no definen nada, porque no abordan el fondo de la cuestión (es decir: qué condiciones ha de reunir un libro determinado para admitir, debajo del título y entre paréntesis, la palabra novela; o qué diferencia hay entre leer una guía telefónica como una novela o como una guía telefónica).

Aunque tal vez el auténtico problema sea dar por sentado que todos los libros que denominamos novelas son, efectivamente, novelas. O dicho de otra forma: tal vez sea un error partir de la premisa de que la palabra novela designa, efectivamente, un género de cosas.

En la Wikipedia, la categoría «Novela» contiene, entre otras, las siguientes páginas: «Novela epistolar», «Novela caballeresca», «Novela de costumbres», «Novela de terror», «Novela de tesis», «Novela del oeste», «Novela filosófica», «Novela gráfica», «Novela psicológica», «Novela realista», «Novela río», «Novela satírica», «Novela testimonio», «Novelas paleocristianas»y «Pulp fiction lésbica» (Categoría:Novela, 11 de octubre de 2015). En los últimos tiempos se habla, incluso, de «hipernovelas»o «novelas hipermedia», expresiones con las que se hace referencia a relatos electrónicos como Golpe de gracia, de Jaime Alejandro Rodríguez Ruiz, donde se integran recursos multimedia como vídeos, juegos, animaciones, música, sonidos y texto para imprimir. ¿Es posible abarcar semejante variedad con una única definición? Si pudiéramos preguntárselo a Wittgenstein, seguramente nos diría que no; y tal vez añadiría que, si queremos saber realmente en qué consisten las novelas, lo primero que deberíamos hacer sería desechar la idea preconcebida de que, cuando diferentes entidades se designan con un mismo término, es porque deben de tener algo en común. El primer paso que deberíamos dar, por el contrario, sería comprobar si hay algo común a todos los referentes de la palabra novela, porque pudiera ser que más bien nos encontrásemos con una «complicada red de parecidos que se superponen y entrecruzan», como en el caso de los referentes de la palabra juego (Wittgenstein, 1988: § 66). Y, de hecho, esto es precisamente lo que ocurre: ni siquiera una definición tan difusa como la del $D L E$ se adapta a todos los usos que se hacen del término, puesto 
que, si la literatura es el 'arte de la expresión verbal', una novela gráfica no es, ciertamente, una 'obra literaria narrativa de cierta extensión', y tampoco lo es una novela hipermedia como Golpe de gracia, «pues articula medios heterogéneos y lo verbal no alcanza un especial relieve ni una función organizadora» (Núñez Ramos, 2016: 77).

Así pues, resulta ocioso buscar una definición universal que abarque toda la extensión (actual y potencial) de la palabra novela. Lo que sí se puede hacer, en cambio, es formular definiciones de menor alcance que sirvan para distinguir diferentes clases de novelas, pero que trasciendan las categorías basadas en rasgos convencionales («Novela del oeste»), temáticos («Pulp fiction lésbica») o estructurales («Novela río») que habitualmente se manejan. Se trataría, en última instancia, de responder a las siguientes preguntas:

1. ¿qué diferentes tipos de experiencia ofrecen los libros que conocemos como novelas?, y

2. ¿qué condiciones ha de reunir un libro para ofrecer tal o cual tipo de experiencia?

Por supuesto, no es en absoluto mi intención aportar en este artículo nada ni remotamente parecido a una respuesta definitiva. Mi objetivo es, simplemente, señalar algunos puntos de partida desde los que emprender la búsqueda.

\section{Hacia una definición}

Por otro lado, debo aclarar que no me interesan todos los tipos de novelas que actualmente existen, sino uno en particular: el que Gonzalo Sobejano definió en los siguientes términos:

[...] obra literaria en prosa, de necesaria extensión, que mediante la narración, la descripción y la interlocución desarrolla una historia formalmente fingida a través de la cual se expone a la conciencia del lector todo un mundo en la complejidad de sus relaciones individuo-sociedad desde una actitud crítica orientada a mostrar los valores de esas relaciones en busca del sentido de la realidad. (Sobejano, 1986: 90).

Me parece que esta definición es un buen punto de referencia, porque, aunque es muy amplia (de modo que puede aplicarse a una gran variedad de casos particulares), señala una cualidad específica que permite distinguir un tipo peculiar de novelas (a las que en adelante, para simplificar, me referiré sencillamente como novelas, sin más precisiones) de todos los demás géneros que designamos con ese nombre. Así pues, mi punto de partida es que una novela es una narración literaria en prosa de cierta extensión que trata, como diría Bateson, sobre «asuntos de relación [...] entre una persona y las que tiene frente a sí, o entre una persona y el ambiente» (Bateson, 1998: 282).

Por otra parte, creo que la definición de Sobejano es igualmente estimulante por lo que tiene de problemático, pues de su formulación se derivan tres cuestiones sobre las que conviene que nos detengamos a reflexionar para no dejarnos llevar por sobreentendidos e ideas preconcebidas. 


\section{1. Tres cuestiones problemáticas}

\section{1. 1. ¿Qué es una historia?}

Dice la definición que las novelas desarrollan «una historia formalmente fingida». Pero ¿qué es exactamente una historia? Según el propio Sobejano (1975: 113), La colmena es una novela «sin protagonista y sin asunto», pero no por ello dejaría de ser una novela. Stevick (1967: 4), en cambio, considera que una novela que no presente una acción coherente y completa con principio, nudo y desenlace no es propiamente una novela. Así, según su criterio, obras como la Historia verdadera, Gargantúa y Pantagruel o Robinson Crusoe caerían fuera de los límites del género, por mucho que en la Wikipedia se afirme lo contrario (Historia verdadera, 16 de octubre de 2018; Gargantúa y Pantagruel, 3 de abril de 2019; Robinson Crosoe, 10 de mayo de 2019).

Pero no nos desviemos: ¿qué es una historia? R. S. Crane propuso una sugerente respuesta en un artículo sobre la trama del Tom Jones. Para Crane (1950), el argumento de una obra narrativa es la síntesis de tres elementos: acción, pensamiento y carácter. Cada uno de estos elementos influye sobre los demás, pero siempre hay uno que funciona como «principio sintetizador», de forma que hay tres tipos básicos de argumento: en el argumento de acción, el principio sintetizador es un cambio en la fortuna del protagonista; en el argumento de carácter, el cambio afecta a su personalidad, y en el argumento de pensamiento, por su parte, lo que cambia son las opiniones y conocimientos del personaje acerca del mundo. Así pues, desde este enfoque, una obra de ficción tiene argumento si a lo largo de su desarrollo se completa algún proceso de cambio, de tal modo que a partir de una situación inicial se llega a una situación distinta.

Pero veamos ahora un caso particular: La novela luminosa, de Mario Levrero; una obra que, aunque es básicamente el diario de su autor, se anuncia como novela en la web de La Casa del Libro, y que, además, ha sido calificada como «una de las novelas más importantes de la literatura latinoamericana de los últimos años» (García, 2010). El libro, sin embargo, termina con un epílogo que comienza con la siguiente frase: «Un diario no es una novela; a menudo se inician líneas argumentales que luego no continúan, y difícilmente alguna de ellas tenga una conclusión nítida» (Levrero, 2016: 561). Unos renglones más adelante, Levrero reconoce que le hubiera gustado que su libro pudiera leerse como una novela, y que tenía «la vaga esperanza» de que «todas las líneas argumentales abiertas tuvieran alguna forma de remate», pero afirma que finalmente no fue así, de manera que, en definitiva, su diario es «una muestra o un museo de historias inconclusas» (Levrero, 2016: 561). Terminado este preámbulo, el autor dedica el resto del epílogo a retomar alguna de esas líneas abiertas. Cuenta que por fin descubrió el archivo responsable de que el Word le censurase la palabra pene, que leyó más libros de Rosa Chacel y que tampoco le gustaron, que no volvió a comunicarse telepáticamente con su librero y que, tal como sospechaba, la causa de sus mareos eran los antidepresivos. O sea, viene a decir que el 27 de octubre de 2002 todo sigue prácticamente igual que el 5 de agosto del año 2000, cuando empezó a escribir el diario: tiene las mismas manías y obsesiones que tenía entonces, no ha conseguido superar su adicción al ordenador, su antigua novia 
sigue sin querer acostarse con él y, tal como se temía, no fue capaz de terminar la novela que tenía pensado escribir.

De forma que, según la definición de Crane, La novela luminosa no tiene un argumento propiamente dicho. Pasan cosas (por ejemplo, en enero de 2001, Levrero consigue, tras múltiples peripecias, comprar un aparato de aire acondicionado), pero lo cierto es que no se produce ningún cambio sustancial en la vida del protagonista. Por otra parte, resulta que, al quedar inacabadas, las historias que se cuentan en el diario tienen un remate plenamente satisfactorio; el único posible, de hecho, para un libro cuyo tema principal no es otro que la incapacidad de sobreponerse a la inercia. ¿Puede considerarse, entonces, que La novela luminosa sí desarrolla una historia, o al menos algo por el estilo? Lo que está claro, en cualquier caso, es que no deja de tener unidad aunque no tenga un argumento dinámico. Es evidente que el libro trata de «asuntos de relación», concretamente de la relación de Levrero con su ciudad, con su trabajo, con sus seres queridos y, sobre todo, con sus propias carencias. Y lo hace desde una actitud (auto)crítica «orientada a mostrar los valores de esas relaciones». Pero esto nos lleva a otra pregunta.

\section{1. 2. ¿Cómo distinguir un libro que trata sobre «asuntos de relación» de uno que no lo hace?}

O dicho de otra manera: ¿cuándo puede considerarse que un libro determinado trata de lo que, según Sobejano, tratan las novelas (o sea, del «sentido de la realidad»)? Podríamos considerar que, dado que todo escritor escribe necesariamente desde su punto de vista, todas las novelas tratan (aunque sólo sea en cierta medida) del modo en que su autor se relaciona con la realidad. ¿Pero significa eso que el contenido de todos los libros que se presentan como novelas es, en última instancia, el sentido de la realidad?

Scholes y Kellogg (Scholes, Phelan y Kellogg, 2006: 82-105) proponen un concepto de contenido que, a mi juicio, complementa muy bien la definición de Sobejano. Para ellos, el sentido de una obra de arte es, básicamente, la relación que es posible establecer entre el mundo ficcional de la obra y el mundo real que habitan el autor y los lectores. Entender una narración, por tanto, quiere decir encontrar una relación satisfactoria entre esos dos mundos, de modo que el lector pueda relacionar su propia experiencia con las situaciones presentadas en el relato. Por supuesto, no todas las narraciones se relacionan de la misma manera con el mundo real. En algunos casos se refiere lo que efectivamente ocurrió, otras veces se presentan personajes y acontecimientos que son inventados pero podrían ser reales, y en otras ocasiones el mundo representado en la obra es una versión más o menos estilizada o intelectualizada del mundo empírico. Incluso hay narraciones (y este es el punto que más me interesa de su teoría) que no guardan ninguna relación relevante con la realidad. Es el caso, por ejemplo, de las novelas de aventuras, donde el interés radica casi exclusivamente en el desarrollo de la intriga y en la repetición de ciertos tópicos asociados al género (triunfo del héroe, derrota del villano, secuencia de acción previa al desenlace, etc.). 
Pero esta ausencia de contenido no se da solamente en el género de aventuras y en otras formas de literatura de consumo. El congreso de literatura (Aira 2012), tampoco guarda relación alguna con el mundo real, porque la historia que cuenta es manifiestamente absurda. En la primera parte del libro, un escritor llamado César Aira se hace rico tras descifrar el enigma del Hilo de Macuto, un artilugio diseñado por unos piratas para señalar (y, al mismo tiempo, esconder) la ubicación de su botín. En la segunda parte, nuestro héroe asiste a un congreso de literatura en Mérida (Venezuela) con el único propósito de clonar a Carlos Fuentes, pues, además de escritor, Aira es un científico loco y su plan para dominar el mundo consiste (por lo que sea) en crear un ejército de superintelectuales. Lamentablemente, su plan no sale como esperaba y, en lugar de a Carlos Fuentes, termina clonando el material genético de su corbata. Como resultado de este error, la ciudad está a punto de ser destruida por una manada de gigantescos gusanos de seda, pero, en el último momento, Aira se las arregla para eliminarlos poniendo en marcha su Exoscopio.

Llegados a este punto se impone una breve digresión. Booth (1983: 125-136) consideraba que todas las novelas ofrecen tres clases de interés:

1. cognitivo (deseo de conocer la verdad, bien acerca de lo que ocurre en la ficción, bien acerca de la vida misma);

2. cualitativo (deseo de reconocer algún tipo de patrón o de disfrutar de alguna cualidad del género que sea), y

3. práctico (implicación emocional en la trayectoria de los personajes).

Pues bien: El congreso de literatura sólo resulta interesante a nivel cualitativo. En poco más de cien páginas de extensión, Aira ofrece a los lectores multitud de situaciones absurdas y giros inesperados, y encontrarse con esos giros y situaciones produce un tipo particular de placer. La imagen de una ciudad arrasada por una marabunta de gusanos azules nacidos de la corbata de un Premio Cervantes es indudablemente cómica, como también resulta cómico el contraste entre los delirantes acontecimientos que se cuentan en el relato y el estilo más bien desapasionado (casi ensayístico, de hecho) del narrador. Pero eso es básicamente todo lo que la obra tiene que ofrecer. Es imposible identificarse con los personajes, porque actúan de forma aleatoria (¿por qué César Aira —el científico loco, no el escritor nacido en Coronel Pringles en 1949 - sigue empeñado en dominar el mundo, siendo así que ya es inmensamente rico gracias a haber descubierto el funcionamiento del Hilo de Macuto?). Por otra parte, el universo del relato no se parece en nada al mundo empírico, y no sólo porque entre sus habitantes se cuentan unos gusanos gigantes originados a partir de la información genética contenida en un accesorio de moda, sino, sobre todo, porque en él no funcionan los principios de causalidad, identidad y no contradicción. Es un universo inestable donde puede pasar cualquier cosa simplemente porque sí. Y esto impide que la narración suscite el interés cognitivo más básico de todos: el deseo de saber cómo termina la historia. En el mundo de Aira es imposible el suspense, porque, hacia la mitad del libro, un lector atento ya no espera un desarrollo coherente de los acontecimientos que dé lugar a un desenlace inesperado pero verosímil. 
Así pues, la experiencia de leer El congreso de literatura no se parece en nada a la de leer $L a$ novela luminosa, $\mathrm{y}$, por lo tanto, podemos considerar que pertenecen a géneros distintos, aunque de los dos libros se diga que son novelas.

Y dicho esto, vamos con la tercera cuestión.

\section{1. 3. ¿Por qué partir de la premisa de que los procedimientos compositivos característicos de la novela se reducen a la narración, la descripción y la interlocución?}

Efectivamente, el principal problema de la definición de Sobejano, a mi modo de ver, es que resulta demasiado restrictiva en lo que atañe a la forma. Si aceptásemos que los únicos recursos narrativos propiamente novelísticos son la narración, la descripción y la interlocución, quedarían fuera de nuestro foco de interés muchos de los grandes clásicos del género (empezando, sin ir más lejos, por el Quijote). En este aspecto, la definición de Sobejano choca con la de Bajtin, que, con ser de alcance más limitado, refleja mejor el carácter transversal de la novela —un auténtico «género de géneros», en palabras de Javier Cercas (2011).

Para el teórico ruso, como es bien sabido, la novela no es otra cosa que «la diversidad social, organizada artísticamente, del lenguaje» (Bajtin, 1989: 81). Considera que, en efecto, el propósito de la novela es explorar las relaciones entre el individuo y su entorno, y es por esta razón que se trata de «un fenómeno pluriestilístico, plurilingual y plurivocal» (Bajtin, 1989: 80), pues el argumento está subordinado, en último término, a la «representación de los hablantes y sus universos ideológicos» mediante la «correlación y revelación recíproca» de los lenguajes que expresan (y configuran) esos universos (Bajtin, 1989: 181). De ahí que la característica más destacada de la novela —siempre según Bajtin - sea la intertextualidad, o sea, el diálogo de géneros, registros y discursos dentro de una misma obra.

Podemos encontrar un caso ejemplar de intertextualidad en Los premios, de Julio Cortázar (Cortázar, 2005). La historia (un grupo de personajes se embarcan juntos en un crucero, que es el premio de una especie de lotería) es claramente un Macguffin que no tiene más propósito que reunir en un mismo escenario a un variopinto grupo de individuos que sería inverosímil que coincidiesen en circunstancias normales. En un momento dado surge un conflicto (por alguna razón desconocida, los pasajeros tienen vedado el acceso a la popa del barco, lo cual provoca un enfrentamiento entre los que quieren averiguar lo que pasa y los que sólo quieren disfrutar del viaje), y así, los personajes se ponen a discutir, revelando sus diferentes personalidades y formas de ver el mundo a través de las palabras con las que se expresan. A medida que interactúan unos con otros, algunos de ellos cambian de mentalidad, mientras que otros se reafirman en su punto de vista. Y, entretanto, el narrador es prácticamente transparente, pues se limita a reflejar la manera de hablar de los personajes.

Ahora bien: puede ocurrir que un libro mezcle géneros y registros sin que necesariamente haya un diálogo entre ellos. Pienso, por ejemplo, en La vida instrucciones de uso (Perec, 2018), citada frecuentemente como una de las mejores novelas del siglo veinte. En la contraportada de la edición 
que tengo encima de mi escritorio en este momento se dice que el libro de Perec es «un compendio tan enciclopédico como la Comedia de Dante o los Cuentos de Canterbury de Chaucer», y efectivamente lo es. En él podemos encontrar un catálogo de artículos de bricolaje, una receta de ensalada de cangrejo, minuciosas descripciones del mobiliario y la decoración de todos los apartamentos de un edificio parisino y, sobre todo, un montón de historias intercaladas que van desde el costumbrismo hasta el relato de aventuras, pasando por el folletín, el whodunit y hasta el realismo mágico. Quizá para subrayar esta variedad, uno de los anexos del libro es, precisamente, un índice donde se listan algunas de ellas, como por ejemplo:

- la historia del acróbata que no quiso bajarse del trapecio;

- la historia del actor que simuló su muerte;

- la historia del antiguo veterinario enamorado de una marsellesa bigotuda;

- la historia del antropólogo incomprendido;

- la historia del arqueólogo que confiaba demasiado en las leyendas;

- la historia del capitán que exploró Nueva Guinea;

- la historia del decorador que tuvo que demoler la cocina de la que tan orgulloso estaba;

- la historia del hombre que compró el Vaso de la Pasión;

- la historia del jefe de almacén que recopiló las pruebas de la supervivencia de Hitler;

- la historia del joyero que fue asesinado tres veces;

- la historia del Lord que ocultaba sus pasiones secretas tras manías ficticias;

- la historia del magistrado y de su esposa que se hicieron ladrones;

- la historia de la mujer que hizo aparecer 83 veces al diablo;

- la historia de la novia cautiva de los berberiscos;

- la historia del pintor que practicó la necrofilia;

- la historia de la señora que se inventó sobrinas;

- la historia del soldado de primera clase más condecorado de Oceanía.

No me parece, sin embargo, que toda esta variedad sea un medio para confrontar diferentes discursos y perspectivas sobre el mundo; más bien creo que se trata de un fin en sí mismo, igual que las escenas absurdas de las novelas de Aira. Por momentos, parece que La vida instrucciones de uso quiere ser una novela realista. En el gusto de Perec por las descripciones y los catálogos se adivina el propósito de ofrecer un documento de la vida cotidiana en el París de los años setenta. Pero más que lo cotidiano, en el libro predomina lo extraordinario. El mundo de la novela no se parece demasiado al mundo real, o, por lo menos, no resulta verosímil, porque (como acabamos de comprobar) está repleto de personajes excéntricos a los que les suceden las cosas más improbables. Y el contraste entre estos dos grandes registros (el realista y el fantástico, por llamarlos de alguna manera) no parece estar encaminado a producir ningún efecto de sentido más allá del propio contraste. No se cuestionan ni se revelan el uno al otro, simplemente coexisten y se alternan. 
Por eso, más que presentar «todo un mundo en la complejidad de sus relaciones individuosociedad», La vida instrucciones de uso presenta varios mundos al mismo tiempo, y esos mundos, aunque se solapan y entrecruzan, son independientes. Mi opinión, entonces, es que el libro de Perec, más que un texto intertextual, es un texto multitextual, o sea, que no es un auténtico texto, sino una miscelánea. Y por eso (si mi lectura es correcta), no sería una novela en el mismo sentido en que lo es Los premios, porque ofrece una experiencia enteramente distinta.

\section{Conclusiones}

Quedamos entonces (de momento) en que las novelas se caracterizan, en primer lugar, por recrear un mundo; bien mediante una narración clásica con planteamiento, desarrollo y desenlace, bien mediante algún otro procedimiento. Ese mundo, además, debe estar configurado de tal manera que el contenido del libro resulte significativo, es decir: un libro no es una novela si no ofrece la posibilidad de que, al hilo de la lectura, el destinatario valore su propia experiencia vital desde una nueva perspectiva.

Ahora bien: ¿mediante qué procedimientos, concretamente, es posible recrear un mundo de tal forma que la lectura del libro produzca ese efecto? ¿Puede leerse como una novela, pongamos por caso, una colección de documentos aparentemente inconexos? ¿De qué manera? ¿Cómo de extensa ha de ser una novela para ser una novela y no un cuento largo? ¿Y cuándo puede considerarse que un libro presenta la complejidad de las relaciones individuo-sociedad desde una actitud lo suficientemente crítica como para funcionar, efectivamente, como una novela?

Son muchas y muy complejas las preguntas que habría que responder para formular una caracterización razonablemente satisfactoria del género. En cualquier caso, creo que las bases que se proponen aquí son una buena referencia para orientarse en la enmarañada selva que conforman las novelas paleocristianas y todos sus parientes próximos y lejanos, pues permiten identificar algunas de las cuestiones que habría que esclarecer para dilucidar si la guía de teléfonos de Madrid pertenece (o no) al mismo género de libros que Soldados de Salamina.

\section{Referencias bibliográficas}

Aira, C. (2012). El congreso de literatura. Barcelona: Random House Mondadori.

Bajtin, M. (1989). Teoría y estética de la novela. Madrid: Taurus.

Bateson, G. (1998). Pasos hacia una ecología de la mente. Buenos Aires: Lohlé-Lumen.

Booth, W. C. (1983). The Rhetoric of Fiction. Chicago: The University of Chicago Press.

Categoría:Novela. (11 de octubre de 2015). En Wikipedia, la enciclopedia libre. Recuperado el 14 de mayo de 2019 de https://es.wikipedia.org/wiki/Categor\%C3\%ADa:Novela.

Cela, C. J. (1953). Mrs. Caldwell habla con su hijo. Barcelona: Destino.

Cercas, J. (2011, 25 de junio). La tercera verdad. Babelia. Recuperado de https://elpais.com/diario/ 2011/06/25/babelia/1308960747_850215.html. 
Cortázar, J. (2005). Los premios. Madrid: Cátedra.

Crane, R. S. (1950). The Plot of Tom Jones. The Journal of General Education, 4 (2), 112-130.

García, G. (2010, 31 de enero). La novela luminosa, de Mario Levrero. Letras Libres. Recuperado de https://www.letraslibres.com/mexico/libros/la-novela-luminosa-mario-levrero.

Gargantúa y Pantagruel. (3 de abril de 2019). En Wikipedia, la enciclopedia libre. Recuperado el 14 de mayo de 2019 de https://es.wikipedia.org/wiki/Gargant\%C3\%BAa_y_Pantagruel.

Historia verdadera. (16 de octubre de 2018). En Wikipedia, la enciclopedia libre. Recuperado el 14 de mayo de 2019 de https://es.wikipedia.org/wiki/Historia_verdadera.

Levrero, M. (2016). La novela luminosa. Barcelona: Penguin Random House.

Núñez Ramos, R. (2016). La identidad de la literatura y las nuevas tecnologías. En S. Bouso González, P. Couto Cantero, R. Núñez Ramos y J. M. Paz Gago (Eds.), La pantalla ficticia. Literatura y tecnologías de la comunicación (pp. 21-86). Madrid: Pigmalión.

Perec, G. (2018). La vida instrucciones de uso. Barcelona: Anagrama.

Robinson Crusoe. (10 de mayo de 2019). En Wikipedia, la enciclopedia libre. Recuperado el 14 de mayo de 2019 de https://es.wikipedia.org/wiki/Robinson_Crusoe.

Scholes, R., Phelan, J., y Kellogg, R. (2006). The Nature of Narrative (Fortieth Anniversary Edition, Revised and Expanded). Nueva York: Oxford University Press.

Sobejano, G. (1975). Novela española de nuestro tiempo (en busca del pueblo perdido). Madrid: Prensa Española.

Sobejano, G. (1986). Testimonio y poema en la novela española contemporánea. En Kossoff, A. D., Amor y Vázquez, J., Kossoff, R. H., y Ribbans, G. W. (Eds.), Actas del octavo Congreso de la Asociación Internacional de Hispanistas: celebrado en Brown University, Providence, Rhode Island, del 22 al 27 de agosto de 1983 (pp. 89-115). Madrid: Istmo.

Stevick, P. (1967). Introduction. En P. Stevick (Ed.), The Theory of the Novel (pp. 1-10). Nueva York: The Free Press.

Wittgenstein, L. (1988). Investigaciones filosóficas. Madrid: UNAM-Crítica. 